Wright State University

CORE Scholar

$5-1996$

\title{
Saying What We Will Do, and Doing What We Say: Implementing a Customer Service Plan
}

\author{
Susan Wehmeyer \\ Wright State University - Main Campus, susan.wehmeyer@wright.edu \\ Dorothy Auchter \\ Arnold Hirshon
}

Follow this and additional works at: https://corescholar.libraries.wright.edu/ul_pub

Part of the Library and Information Science Commons

\section{Repository Citation}

Wehmeyer, S., Auchter, D., \& Hirshon, A. (1996). Saying What We Will Do, and Doing What We Say: Implementing a Customer Service Plan. Journal of Academic Librarianship, 22 (3), 173.

https://corescholar.libraries.wright.edu/ul_pub/155

This Article is brought to you for free and open access by the University Libraries at CORE Scholar. It has been accepted for inclusion in University Libraries' Staff Publications by an authorized administrator of CORE Scholar. For more information, please contact library-corescholar@wright.edu. 
Saying What We Will Do, And Doing What We Say: Implementing A Customer Service Plan

by Susan Wehmeyer, Dorothy Auchter, and Arnold Hirshon

The corporate literature on customer service has much to offer academic libraries. A customer service plan can improve customer relations and internal operations, and empower the frontline staff to meet customer needs. This article explores the practical aspects of the development of a service pledge at the Wright State University Libraries.

Susan Wehmeyer, Head, Information Delivery Services, Fordham Health Sciences Library Wright State University, Dayton, Ohio 45435 <swehmeyer@library.wright.edu>. Dorothy Auchter, Reference Librarian, Paul Laurence Dunbar Library Wright State University, Dayton, Ohio 45435 <dauchter@library.wright.edu>. Arnold Hirshon, Vice Provost for Information Resources (formerly University Librarian, Wright State University, Dayton OH) BA East Packer Avenue, Lehigh University, Bethlehem, Pennsylvania 18015-3170<arh5@lehigh.edu>.

In the corporate sector, a customer service strategy has become a vital component of business success. The business literature abounds with articles about companies that improved their competitiveness by increasing their attention to customer service planning. Companies known for high quality service, attention to detail, and a sincere interest in customer relations engineered their success through formal plans to ensure customer satisfaction. Good service adds value to library resources. For example, a good collection of journals is useful, but a good collection that is available in a timely and consistent manner is much more useful. Economics offers a compelling reason for academic libraries to seek ways to apply successful corporate customer service strategies. As colleges and universities face tighter financial situations, academic libraries must seek budgetary allies on campus. Satisfied customers are more likely to defend the library budget. Academic libraries face challenges from both internal and external competitors as the information industry expands. A good customer service plan will help position the library as the supplier of choice for information services. In the university setting, the "customers" are chiefly students, faculty, and staff, often referred to as "patrons." Although any commonly understood term is acceptable, this article will use the term "customer" because of its greater association with economic support. In daily use, this term has an added advantage: it reminds staff that the client is not just altruistically "patronizing" the library, but also expects and deserves good service. Another aspect related to business is that in the past, many businesses operated under the assumption that a knowledgeable staff and quality resources would naturally result in good 
customer service. However, recent corporate experience demonstrates that an active approach to service is more effective for satisfying customers and strengthening customer loyalty. Customer loyalty is very important. University libraries may fall into the trap of believing that they are operating within a captive market. It is important to realize that the absence of a direct competitor does not mean that customers automatically will develop loyalty for the library. The library must establish its reputation within the university community as being responsive, user friendly, and efficient if it is to win allies among the faculty and student body.

This article will first review the general business literature on customer service planning, and focus on one aspect, the customer pledge as it was developed and implemented at the Wright State University Libraries.

\section{CUSTOMER SERVICE PLANNING LITERATURE}

Service planning concentrates the energy of the organization on the delivery of services to the customer, and redirects the focus of internal operations on customer needs. A customer service pledge is only one part-but a vital part-of an overall customer service plan. The plan includes the entire spectrum of customer service improvement efforts, such as the means to derive customer input and satisfaction (surveys, focus groups, etc.), staff customer-service training programs, and organizational response mechanisms. The customer service pledge is a published statement, prepared after consultation with all staff, that articulates the intentions of the organization to provide meaningful and measurable levels of quality services. The pledge may contain both broad services, as well as specific and objective criteria by which to judge how adequately the organization is meeting those goals. For example, the pledge may contain the goal "to provide prompt service to every customer," but a specific objective such as "we will call you back if we need to ask you to hold on the phone for more than 3 minutes" is what gives the goal real meaning. The development of a service plan begins with a survey of the market to determine what the customer wants, and thereafter to determine services the organization will offer to meet those needs. Formal service plans are statements of expected performance against which actual performance will be measured. A customer service plan is an outline of the internal operations necessary to support the services offered by the organization. The plan includes standards for measuring the level of achievement. It is customer driven and results-oriented. Karl Albrecht asserts that service should be viewed as a product. He promotes the concept of service management, defined as "the total organizational approach that makes quality of service, as perceived by the customer, the number one drivin force for the operation of the business." Strong customer service deserves careful advanced planning, rather than merely responding to problems. John Tschohl discusses the shifts in management philosophy that must occur when implementing a service plan. ${ }^{3}$ Traditional management primarily concerns itself with the product or service the organization supplies, but it is the customer's response to these services that is the crucial ingredient. By organizing around a customer service plan, this goal is kept in a prominent position. Each department must look beyond the immediate concerns of budgets, staffing, and logistics to consider the impact on the customer. The development of a customer service plan requires the organization to position customer service as a central activity, rather than as a clerical function to handle the occasional customer complaint. Many monographs and some articles in the business literature offer practical advice on the steps to be taken in constructing a customer service plan. ${ }^{5}$ Most of these books were written for the profit making sector. More 
recently there have been a few that briefly addressed these questions in library operations. The literature about customer service plans comes to a consensus on the following underlying thoughts:

- $\quad$ Frontline staff are the vital link. Staff have the most direct contact with the customers, and must have a genuine commitment to customer service. To fulfill their responsibilities, staff must be empowered with the knowledge and authority to address a wide variety of customer needs, and must have adequate materials and resources to carry out their jobs.

- $\quad$ Service is a product. Service not only has a tremendous impact on the perceptions about an organization, but it also adds value to the organizational resources by enabling customers to use those resources effectively.

- $\quad$ Understand your customer. Only through formal research such as surveys and focus groups can the organization determine which services are important to the customers.

- $\quad$ There is no quick fix. Employee pep rallies, smile training, and snappy slogans will not result in the establishment of long-term, reliable, and effective customer service. A thorough review of procedures, careful planning and employee training are vital to lasting improvements in customer service.

To emphasize the pivotal role of the frontline staff, Albrecht advises turning the traditional organizational pyramid upside-down. For the organization to commit fully to putting the needs and convenience of the customers first, customers must be at the peak of the pyramid. The concerns of the frontline employees should receive next consideration. As frontline employees are often the only staff whom the customers see, the quality of service hinges on their skills. These staff must have the necessary training and equipment to take care of the customers, with the customer receiving as little runaround as possible. Staff must develop ownership of the customer's problems, with no option to "pass the buck" to someone else. With such high expectations of the frontline staff, the rest of the organizational structure should be geared towards their needs. To achieve these ends, frontline staff should be an integral part in establishing the service plan. They will have many valuable insights into the procedural issues, possibilities, and limitations of the organization. Perhaps even more importantly, staff involved in the planning process become invested in the program. This is vital for the plan to succeed. No customer service plan can work if the individuals who have the most contact with the customer do not have a genuine commitment to the principles of service, as well as the familiarity with the actual procedures to carry out their job. Participation in the development of the plan will help in both areas. The focus of a customer service plan is on the internal operations. Albrecht recommends breaking the service plan into segments by department. Each department must evaluate its services, determine a realistic level of expectation, and define its objectives. These departmental objectives become the basis for the service plan of the entire organization. By requiring each department to evaluate its role in customer service, the organization avoids the trap of placing the entire burden for customer relations on the frontline staff or on a separate "customer relations" supervisor. Inefficiencies that adversely affect customer service often lie deep within the organization, and frontline employees must mediate these situations with the public. In the absence of procedural reviews to remedy these problems, any "solutions" implemented by the frontline staff may merely be a quick fix. There are some quick fixes that do have valid purposes, such as customer surveys, suggestion or complaint boxes, and slogans. However, when these solutions are used in isolation from a complete customer service plan, they 
can become outlets for customers to channel their frustrations, but will bring little concrete improvement in the lasting reliability, responsiveness, and quality of the organization. When preparing a customer service plan the process must include a major evaluation of both the customer's needs and the organizational procedures. It often will be discovered that existing procedures had been established by "common law," otherwise known as undocumented policies created in response to particular problems or crises. Such practices rarely take the entire organization into consideration, and they may linger long after the problem for which they were developed disappeared. A major benefit of customer service planning is the weeding-out of such policies and practices. The United States government is learning from the corporate example. In recognition that most of the government's bureaucracy was structured "to please the boss," the government is changing things to please the customers. The National Performance Review Commission appointed by President Clinton to reinvent government recommended that all agencies develop customer service standards and make them available to the public. As of this writing, all national agencies of government, from the Department of State to the National Cemetery System, have been charged to establish service standards. Based upon customer input, each agency has a pledge that concisely states the services the public can expect from the agency. For example, the Post Office publicized that it will deliver first class mail to anywhere in the world in three days, deliver first class mail locally overnight, and customers will receive service at post office counters within five minutes. These standards are measurable, achievable, readily understandable, and of value to the customer. They are jargon-free statements that inform the customer about the services they may expect. Undergirding the public pledge is an internal customer service plan that spells out the strategy for achieving these standards. Although there has been some attention to the place of customer service in the information field, library literature is sparse on the topic of formal customer service planning, and on service pledges in particular. For example, a recent inquiry posted to several listservs about customer service plans produced no results. What has been published in the library literature echoes much of the business literature recommending advance planning, including research into customer needs and attention to frontline staff. There are two recent books in the library and information services literature that address customer service. In Customer Service: A How-To-Do-It Manual for Librarians Suzanne Walters primarily emphasizes the importance of researching customer needs through such steps as defining the question, determining the most appropriate data to the question, selecting a sample population, and interpreting the data. The book also stresses the importance of leadership in customer service. Walters says, "The essential ingredient for customer service lies in the leadership and management philosophy of the organization." ${ }^{12}$ In other words, good customer service does not just happen, but requires careful planning, training, and implementation. More relevant to the specific topic of customer service pledges is Customer Service in the Information Environment, by Guy St. Clair. ${ }^{13}$ The book provides general advice on how to survey customers, and to design a customer service plan and measure its effectiveness. St. Clair stresses the importance of the active participation of all staff because staff have valuable insights as to the way things really work. If the plan is seen by staff as a disciplinary device or criticism of their service, the plan will be doomed to failure. ${ }^{14}$ Before crafting a service plan, the organization must engage in systematic research to establish the needs of the customer and the current internal operations of the organization. A common problem at the beginning of customer service planning is defining the customer's level of expectation. ${ }^{15}$ Never make assumptions 
about what the customers want from an organization. For example, the Oregon Department of Motor Vehicles made an assumption that its customers would be chiefly concerned with the length of the service line. To their surprise, the research showed that the major concern of customers was with unflattering photographs on their drivers licenses. They modified their service to include a choice of snapshots. To establish service priorities, Albrecht suggests three research techniques: indepth interviews with individual customers, focus group interviews with

selected customers, and statistical surveys of representative customer populations. ${ }^{16}$ The first two techniques are good for determining customer perceptions of the organization and its services.

Statistical surveys are useful for gathering perceptions from a large cross section of the population. A survey can reach far more people than interviews and focus groups, and provides a more valid and reliable statistical sample.

\section{THE CASE FOR THE CUSTOMER PLEDGE}

As noted earlier, some companies share their service plans with their customers in the form of a customer service pledge, which serves as a public commitment to provide specific services at or above a minimum standard. It is usually a brief document, written from the customer's point of view. A customer service pledge is the most visible part of the customer service plan, with the public promises supported by the service plan foundation. Although the concept of a service pledge is new to libraries, it has numerous adherents in the business sector. In his book, Reengineering Management: The Mandate for New Leadership, James Champy talks about companies that illustrate this concept. Detroit Edison, for example, looked at response time after power goes out in a storm. The company realized that from the customer's perspective, the average response time that is measured by managers is not important. Thus, the company set its objective at zero mistakes.

\section{Developing A Customer Pledge: The Wright State University Experience}

If the library literature, and the lack of response to inquiry on several listservs is an indication, the Wright State University Libraries have unusual practical experience for an academic library in developing and publishing a customer pledge. The balance of this article will explain the experiences of the Wright State University Libraries with this process, from the decision to develop a pledge to its publication. The authors will conclude with recommendations for other libraries contemplating a similar approach. The Wright State University Libraries comprise the academic, health sciences, and music libraries serving a student population of about 17,000, including graduate and doctoral programs. A standing goal of the Libraries is continuous selfimprovement. Prior to the development of the customer service pledge, the professional staff discussed paradigm shifts in information science, and concluded that an active approach with a long-term view was necessary to maintain the library as the primary information provider on campus. Although previous customer surveys revealed very high levels of satisfaction with most library services, the staff recognized that competition from electronic publishers, electronic document delivery, the Internet-for-profit sector, and other private and on-campus providers could quickly alter customer perceptions. Unlike the legendary Swiss watch manufacturers who failed to understand and prepare for the digital watch revolution, most library staff eagerly embraced technology and guided customers through many new electronic information services. It was in this context of improvement, rather than as an approach to an ongoing problem, that the 
libraries first discussed the idea of a customer pledge. The library administration and department managers met at a retreat in late 1993 to review service plans for 1994 and beyond. Plans for a new comprehensive customer survey and a series of focus groups were already well underway. This managerial planning group agreed that the libraries' public relations was an area that could be improved. Although customers seemed satisfied, they did not seem to recognize fully the value of the services they received. This led to the question: what is good service? In personal experience, most of the group recognized good service as occurring when the organization delivered what it promised. Therefore, it was imperative to establish for both the library staff and the customers a shared benchmark that would define the level of service that we would promise to our customers. One prominent example of an organization that does deliver what it promises are the Wal-Mart stores, which determined that a major frustration for its customers were long lines. They promised a solution by posting signs at every check out lane: whenever there were more than three people waiting in line, they would open another register until all lanes are open. Every time a store clerk opened another lane, the customers received a visible signal that their needs were paramount. In the Wright State libraries, the planning group agreed that library customers deserved to have a similar feeling of satisfaction with service. Although the group was not aware of any other libraries that had made a public pledge, $2^{\circ}$ there was some inspiring precedent discussed earlier in the federal government. In particular the pledges of the Postal Service and the Internal Revenue Service seemed to be the most similar to our situation. Once the planning group agreed in principle to writing a customer pledge, the library administration made clear that the implementation of such a plan required the involvement of all staff. As the first step, department heads were to take the idea back to frontline staff. All staff from all departments were to be included in developing definitions of their primary customers and services, and identifying measurable standards of excellence for their areas of service. This groundwork served as the basis for the development of more detailed service plans that involved extensive cooperation between the various libraries on campus and between parallel departments in those libraries.From the outset, staff were aware that the service plans were to be complete documents for internal staff use, but that the libraries would publish and distribute widely to customers the primary external service objectives that were relevant to our customers. Staff were to write the service goals and objectives in such a way that the core commitments could be posted on a sign at every service point, with the complete pledge available to the customer in a printed brochure.

\section{Effect of the Planning Process on Staff}

The impact of the planning process on the University Libraries' staff was farreaching. Not only was the final document important, but the process was invaluable because through an iterative process we were able to have staff articulate standards that were commonly held by multiple departments. Staff came to realize that there was widespread agreement at all levels as to our priorities. Of equal importance, the administration of the academic and health sciences libraries had been brought together in 1992, and through this exercise staff were able to gain a greater realization as to the commonalities of service between the two libraries. Preparation of the pledge also brought to the surface some staff frustrations that were important to resolve if we were to meet our service commitments. Some staff had become rather frustrated with the everchanging technology, and they resisted the changes as a way to protect the customer from experiencing similar frustrations. The planning process helped to alleviate this problem by 
incorporating the methods to deliver good customer service into the goal setting process. The articulation of customer service expectations ultimately helped reduce stress because it clarified for staff and customers what the library believed it could deliver. Eliminating the ambiguity also relieved the pressure to perform too many services for too many people. This, in turn, empowered the staff to generate priorities for their work based on the service plan. While library administration obligated itself to provide the support necessary to meet the commitments, each member of the staff was ultimately accountable. To ensure both accountability and the opportunity for recognition of good service, all staff of the Libraries can be identified because they wear professionally produced name tags. The planning process also intensified ongoing efforts to respond to customer needs, and resulted in a number of customer-centered improvements. For example, previous customer surveys identified photocopying services as the one area most needing improvement in the libraries. This situation was complicated by the fact that photocopiers were neither owned nor serviced by the libraries. Spurred by customer demand, library staff mounted a persistent campaign with the responsible department on campus to gain improved copiers and copier service.

\section{Preparing the Public Pledge Document}

With the individual departmental goals in hand, the managerial group met as a committee-of-the whole to merge the departmental service plans into broad categories. One category included commitments that applied to all staff in all departments, such as being courteous and listening carefully. Other categories addressed services grouped by customer service area, such as "collections and electronic information services." We were careful to organize these services in a way that made sense to the customer, and not by the names of specific library departments. Each category included the commitments, phrased as specific and measurable objectives. We developed certain principles and conventions to guide the style as we began to prepare the final published pledge.

- $\quad$ The pledge would be phrased from the perspective of the customer, not of the staff. Therefore, the pledge had to organized by type of service rather than by internal library departmental organization, and be phrased clearly and free of buzzwords or ambiguous statements. The document also had to be comprehensive to include all libraries and services.

- The pledge was to be phrased positively, telling the customer what we could or would do, not what we could not provide.

- The standards had to be specific and measurable, particularly about timeliness of services.

- $\quad$ The pledge would address all areas of operation, including internal customer services such as acquisitions, cataloging, and other processing functions that have a direct effect on external customer services.

- $\quad$ The commitments were to be achievable but would stretch us to do more than we did in the past. We knew customers would be delighted to get more than expected, but would feel cheated to receive less.

- $\quad$ The entire pledge would be concise, fitting on a single side of a single sheet of paper.

- A permanent sign, highlighting the core of the pledge, would be prominently displayed at each service desk. 
- $\quad$ The document was to reflect not only an organizational commitment, but also a personal commitment on the part of all staff.

A copy of the pledge and specific service objectives appear in the appendix of this article.

To generate the final document, the planning group prepared a series of draft statements over a period of three months. Staff involvement in the process of determining the contents of the pledge was essential, but staff understood that their exact wording might be changed in the editing process to ensure that the final document would be understandable by our customers. Staff comments and suggestions were encouraged after each draft. The precise phrasing of each statement became the most difficult task of the process because words do matter. We thought it was essential to ensure that there was common agreement on the principles behind the phrases. Some phrasing issues were particularly difficult to resolve. For example, only one of the core commitments in the pledge was written in the negative as, "We will not give you the runaround." Although this statement is the only negative phrase in the pledge, no other wording had such clear meaning or offered such impact from the customer's point of view. Additionally, early drafts of the pledge contained more references to words such as "accurate," "prompt," and "careful." These words were essential to use in the core commitment, but care was taken to establish a more specific standard in the body of the pledge. For example, although the pledge promised "prompt," service, this received more detailed definition in the specific service objective that "we will acknowledge you immediately at any service desk and serve you within 3 minutes or call additional staff."

\section{FROM THEORY TO PRACTICE: PUTTING THE PLEDGE INTO ACTION}

The temptation to revise the customer pledge endlessly was resisted with great difficulty. However, with the basic principles in place, additional refinements could be added later with the benefit of practical experience. Almost nine months after the process started, the pledge was ready for distribution. A meeting of all staff was held prior to the first distribution. Each statement in the pledge was read and explicated to provide the intent of each promise. The theme of the meeting centered around the critical importance of each staff member to each transaction. Above all, staff were encouraged to avoid "passing the buck" or "passing blame." Staff were asked at the meeting to identify any potential implementation problems and solutions that remained in the final draft. Even with the heavy involvement of all staff from the beginning of the project, understandably there continued to be some anxiety about the ability of the Libraries to fulfill all of the promises expressed in the pledge. This was a natural and expected reaction because the goals committed staff to stretch consistently to do more than in the past. Although care was taken not to create expectations that could not be delivered, the pledge was acknowledged as a work in progress. The goal was to improve continuously the University Libraries. As a result, staff were expected to review and update the customer service plans quarterly, and adjust the standards in practice as necessary. Copies of the pledge were printed as a single-fold brochure. The inside opened to a boxed section of our core commitments (goals) and each of the specific objectives was enumerated within general categories. To make good upon our intent to demonstrate a personal commitment to the plan rather than just the commitment of a faceless organization, the front cover included a statement introducing "our commitment to customer service" signed by the university librarian. A picture of the entire staff, 
which was unavailable for the first printing, appeared as the cover photo with the second edition. The back of the brochure included the names, phone numbers and email addresses of all management staff.

\section{Effect of the Pledge on Service Delivery}

Some staff originally were concerned that customers might view the document as an opportunity to look for flaws in service. Not only has this not proven to be the case, but to the contrary the comments from customers about the pledge were quite positive. However, to meet the commitments made in the pledge, some routines and workflow had to be adjusted to enable staff to meet the promises in the pledge. For example, to fill requests for material that had been sent to the bindery, an interlibrary loan procedure had to be instituted to procure rush photocopies of articles within 48 hours. To meet the commitment to serve customers within three minutes, the reference department gave non-intrusive beepers to the roving librarians so that they could be called back to the information desk as needed. Other changes were implemented to provide staff with the skills and tools necessary to meet our pledge, such as providing highend networked computer workstations for every library staff member, instituting job exchange experiences for staff in parallel departments between the main and health sciences libraries, and undertaking training and mini-workshops to introduce new databases and computer programs. The most important internal changes occurred on the individual level. The process of writing and implementing a customer pledge clarified the mission of the University Libraries, and kept the pledge in the forefront of the workday. Perhaps most importantly, the team atmosphere became enhanced. Everyone is equally responsible for meeting our shared commitments, such as ensuring that the customer is served within three minutes. A line at the desk can no longer be dismissed by "it's not my shift," or "it's not my job."

\section{Monitoring Progress on the Promises}

Saying that everyone is responsible for customer service does not make it so. How does the library ensure compliance with the substance of the pledge? Two key factors guarded against broken promises: the level of interest and enthusiasm evidenced by the staff, and the use of tracking mechanisms. The obligation to maintain a balance of both factors was delegated to the department level, with the understanding that the time required to track progress would not prevent staff from providing the customer with good service.

\section{EVALUATION}

Continuous monitoring throughout the year was important, but it was also important to review overall performance after the first year. To undertake this evaluation, some departments developed formal and regular statistical records to monitor their performance, while others relied chiefly on informal or casual observation. In many instances, departments measured compliance with the service pledge by subjective means, such as whether there had been a decrease in problems or complaints. The results of this measure are often self-evident. For example, if current periodicals were not shelved within 24 hours of receipt as promised, one would be able to See the items waiting to be shelved. Comments and suggestions received from patrons also provided a type of subjective feedback. In some cases, formal statistics were kept when the 
objective called for a measurable response, such as turnaround time. To determine whether incoming calls to the circulation desk were routinely concluded within three minutes, the university telephone center generated for the department head an automated log of incoming logs listing call duration. Similar logs were used to make sure that service requirements were being met for quiet study areas, photocopy supplies, and reshelving of books after circulation. The University's Center for Urban and Public Affairs was contracted to conduct multiple focus group sessions and surveys on behalf of the Libraries, in part to determine the effectiveness of the plan. Their report helped to identify areas in need of more attention, points of satisfaction, and general reactions to the customer service pledge. After the service pledge was public for a year, managers were asked to examine formally their level of compliance, and to share their tracking methods with the heads of the other departments. Although final conclusions have not yet been drawn regarding the overall level of compliance with the pledge, the preliminary results shared with all staff indicate that the plan has been very successful in achieving its purpose.

Evaluating the Product

Because the Wright State University Libraries' service pledge was planned to remain a "work in progress," the process of evaluating the effectiveness of the statement has also been ongoing. During the first year, staff examined the pledge quarterly to determine whether any changes were necessary to the document. By the end of the first quarter, feedback from staff indicated that the library could not deliver as promised on all objectives $100 \%$ of the time, but compliance was still very high and probably higher than staff originally expected. The management group retained confidence that all of the goals would be achieved in time. The group decided to look upon the pledge statements as standards the library was committed to reach. As a result, the commitments were left in place without change. Customer input to evaluate the effectiveness of the pledge was solicited during the first year in focus group sessions. The difference between student and faculty perceptions was interesting. Student groups had very positive comments about the statement in their focus group sessions. They saw the pledge as a response to student needs and concerns, and felt it was a positive effort to keep the staff accountable to the customers. Faculty expressed concerns that the commitment was not sincere as the promises were too ambitious, but no specific examples were cited. The observation is particularly interesting because there is ample evidence that the Libraries are already significantly meeting the demands of the pledge, and, therefore, exceeding customer expectations. Additional focus groups in the future should provide more insight into the customer reception of the pledge.

\section{Evaluating the Process}

The process of developing a service pledge for the Wright State University Libraries worked very well. The planning, as well as the final document, had a positive impact on both the staff and library services. The effort was an excellent means to develop and engineer improved service on a library-wide scale. An examination of the process with a critical eye generated no significant regrets. However, a few observations made in hindsight may be instructive.

- We gained a new perspective on the advice of the business literature to "under promise and over deliver" given the perceptions of some faculty that the goals expressed in the pledge were overly ambitious. 
- It is as important that the customer believe that the promises in the pledge will be delivered as it that the staff actually deliver upon them.

- $\quad$ The Wright State University Libraries decided not to "test market" the brochure with customers before publication because we had recently completed a comprehensive user survey and because the process had already become so lengthy. In our case, the need to put something in the hands of the customer quickly became of critical importance so the initiative would not be lost. Other libraries may wish to set aside time for such testing in their initial planning stages.

\section{KEYS TO ENSURING SUCCESS}

The most important consideration in planning a customer service pledge is to produce the document within the larger context of the development of an overall customer service plan. Other essential considerations culled from practical experience and supported by the business literature include:

- $\quad$ Lay the groundwork. Incorporate staff participation at the outset. Investigate customer needs to determine which services they believe are the most important. Identify the desired outcomes concerning what should the customer understand and believe after reading the pledge and what should staff understand having prepared the statement.

- $\quad$ Review the finished product against library goals. Consider whether the plans and policies of the library support the promises in the pledge.

- $\quad$ Gather customer feedback. Testmarket the pledge with a customer survey or focus groups to ascertain whether the finished product provides the desired outcome.

- $\quad$ Invest in professional looking public relations material. If the skills to create a professional brochure or signs do not exist in the library or university, contract the job to someone who does have the skill. A professional-looking presentation supports the perception that the promises in the document will also be carefully attended.

- $\quad$ Make staffing for customer service a priority. Hire new staff based upon their customer service abilities. Regularly review service goals with current staff. Incorporate an expectation of individual commitment to customer service into the human resources evaluation process. Empower employees to make decisions on the frontline that are consistent with meeting the stated objectives in the pledge. Ensure that management staff set a good example by meeting the same commitments in their customer contacts.

- $\quad$ Consider the pledge to be a work in progress. The commitment to customers must change with the times, and the pledge must change with it. Regularly revise the pledge with input from staff and customers.

\section{CONCLUSION}

Improving customer service is not simply a passing fad. As the information industry expands, good customer service plans and pledges are essential to help academic libraries develop a core of satisfied customers, to offset the challenges from both internal and external competitors, and to enable the library to build budgetary allies on campus. Improving customer service is a complex process, of which the development of the pledge is only a part. Once the pledge is prepared, there must be continuous staff training, and changes in local procedures. Perhaps most importantly in our experience was that the process of developing a customer service pledge was as important for the staff as the finished product was for the customers. Through the 
process we began to change our perceptions and cultural values. Staff developed a common understanding of what constituted good service and became empowered to place their work into priority order based on the service plan. A high level of staff enthusiasm, non-intrusive tracking mechanisms and public attention combined to position the customer service pledge as the focus of the work day. The planning that went into the preparation of the pledge has yielded palpable benefits for both staff, and, most importantly, for our customers.

\section{APPENDIX}

Wright State University Libraries' Customer Service Pledge

Note: The following version is dated Fall, 1995. The most current version of the pledge can be found on the World Wide Web at http://libnet. wright.edu/policies. The printed brochure is printed landscape on an $8 \mathrm{Y} 2 \mathrm{X}$ II inch sheet, folded at the center. The description below is in four parts: front cover, inside sidebar, inside text, and back cover.

(FRONT COVER) Our Commitment to Customer Service To the Wright State University Community: The University Libraries are firmly committed to providing excellence in customer service. Inside you will find our general standards of excellence for the libraries and our specific standards of excellence for each service area. We will continually evaluate and update these standards. We value your opinions. Please give us your comments and suggestions, and we will respond.

Sincerely,

Arnold Hirshon

University Librarian

(INSIDE SIDEBAR) Commitment to Excellence

- We will provide courteous, prompt, and accurate service to every customer.

- $\quad$ We will carefully listen and respond to your needs.

- $\quad$ We will provide resources to meet your research needs.

- We will offer opportunities for instruction about our resources and services.

- $\quad$ We will provide an environment conducive to study and research.

- We will not give you the runaround. We will provide the assistance you need, or we will put you in contact with someone who can.

(INSIDE TEXT) We pledge to:

\section{General Services}

- $\quad$ Acknowledge you immediately at any service desk and serve you within 3 minutes or call additional staff.

- $\quad$ Call you back if we need to ask you to hold on the phone for more than 3 minutes.

- $\quad$ Report photocopier problems to the University Printing Services immediately.

- $\quad$ Respond personally to your signed suggestions within 5 working days.

- $\quad$ Make the names and phone numbers of supervisors available at all service points.

- $\quad$ Provide users with the tools and training to enable access to the University Libraries'

collections and to resources available nationally.

- $\quad$ Publicize changes in our services and provide opportunities for training for new services.

- $\quad$ Maintain quiet in designated study areas.

- $\quad$ Provide a clean and comfortable study environment.

\section{Collections and Electronic Information Services}


- Ensure that our collections support the instructional and research mission of Wright State University.

- $\quad$ Ensure the high reliability of the LIBNET system, including workstations capable of printing and/or downloading.

- $\quad$ Catalog materials accurately and promptly.

- $\quad$ Make new books available within 4 weeks of receipt and provide rush delivery when necessary.

- $\quad$ Meet your research needs when materials are at the bindery by locating acceptable substitutes immediately or providing copies within 48 hours.

- $\quad$ Respond to faculty book orders within 5 working days.

- Meet each faculty representative or department chair at least once each quarter to review academic needs.

Reference and Research Services

- $\quad$ Provide professional reference service to facilitate your successful use of library services, resources, and collections.

- $\quad$ Offer scheduled appointments for extended reference consultations .

- $\quad$ Complete database search requests within 2 working days.

- $\quad$ Respond to online reference inquiries within 1working day.

- $\quad$ Assist faculty by developing presentations tailored to the needs of a class.

- $\quad$ Assist faculty by providing reference support for specific assignment.

Information Delivery Services

- $\quad$ Check out and check in all books and materials accurately and efficiently.

- $\quad$ Fill OhioLINK requests within 2-3 days.

- $\quad$ Place your interlibrary loan requests within 2 days.

- $\quad$ Shelve current periodicals within 24 hours of receipt.

- $\quad$ Re-shelve books and bound periodicals within 24 hours of use and regularly maintain shelving order.

- $\quad$ Re-shelve current periodicals within 1 hour of use.

- $\quad$ Complete search requests within 24 hours

Special Collections Services

- $\quad$ Conduct an initial interview with you to meet your research needs most efficiently.

- $\quad$ Locate materials housed on site within 5 minutes.

- $\quad$ Complete photocopies of special collection materials within 48 hours.

- $\quad$ Respond to telephone questions within 24 hours.

- $\quad$ Submit requests for photographic copying to Media Services within 24 hours and send copies to you within 24 hours of completion.

(BACK COVER) If you have any suggestions to improve this customer service statement or our operations, suggestion boxes are available on LIBNET and in the lobbies of both libraries. In addition, please contact: [see WWW version for names, titles, phone numbers, and email addresses of the University Librarian, Associate University Librarians and Department Heads.] 


\section{REFERENCES}

1. E. Patricia Birsner \& Ronald D. Balsley, Practical Guide to Customer Service Management and Operations (New York: AMACOM, 1982), p. 173.

2. Karl Albrecht, At Americas Service (Homewood: Dow Jones-Irwin, 1988), p.20.

3. John Tschohl, Achieving Excellence Through Customer Service (Englewood Cliffs: Prentice Hall, 1991), pp. 34-38.

4. Warren Blanding, Customer Service Operations (New York: AMACOM, 1991), p. 32.

5. Birsner \& Balsley, Practical Guide; Martin Christopher, The Customer Service Planner (Oxford: Butterworth-Heinemann, 1992).

6. Albrecht, At Americas Service, pp. 105-109.

7. Ibid., pp. 131-142.

8. Birsner \& Balsley, Practical Guide,p. 154.

9. National Performance Review, Standards for Serving the American People (Washington D.C.: Government Printing Office, 1994 ), p. 2.

10. Posted request for information from libraries that had either published a public customer service pledge, or were in the process of writing one to PACS-L, LIBADMIN, LIBREF, and MEDLIB-L listservs on August 16, 1995.

11. Suzanne Walters, Customer Service: A How-To-Do-It Manual for Librarians (New York: Neal-Schuman, 1994).

12. Ibid., p. 19.

13. Guy St. Clair, Customer Service In the Information Environment (London: Bowker-Saur, 1993), pp. 104-117.

14. St. Clair, Customer Service, pp. 54-57.

15. Tschohl, Achieving Excellence, p. 36.

16. Albrecht, At Americas Service, p. 162.

17. James Champy, Reengineering Management: the Mandate for New Leadership (New York: HarperBusiness, 1995).

18. Ibid., p. 136.

19. Joel Arthur Barker, Future Edge: Discovering the New Paradigms of Success (New York: William Morrow, 1992), pp. 15-17.

20. More recently, the articulation of standard service levels was discussed very briefly within the context of training, but not as part of a customer service plan, in Julie Brewer, "Service Management: How to Plan for It Rather than Hope for It," Library Administration and Mangement (Fall 1995), pp. 207-210. At page 209, Brewer observes that "Effective training begins with established service level agreements. Specific examples include the number of rings allowed in answering telephones or the level of instruction provided at the information desk before making referrals." While Brewer states that "[s]ervice standards need to be published and communicated throughout the organization," we could find no examples of published statements by an academic library other than the one described in this article. In an electronic mail correspondence with Brewer (December 14, 1995), she could provide no examples from academic libraries. 